\title{
Characteristics of Two Lysine-independent Strains of Streptococcus faecalis
}

\author{
By D. P. GILBOE*, W. G. SMITH AND L. M. HENDERSON \\ Department of Biochemistry, College of Biological Sciences, \\ University of Minnesota, St Paul, Minnesota 55101, U.S.A.
}

(Accepted for publication 12 April 1969)

\begin{abstract}
SUMMARY
The ease of isolation of two mutants of Streptococcus faecalis 8043 appeared to be the result of the presence in the parent strain of a system for slow synthesis of lysine. The mutation to lysine independence occurred when the population became large enough for a significant number of spontaneous mutational events to occur. The slow growth and lysine depletion lysis of the parent strain selected for the new strain. The hydroxylysine-resistant mutant can arise from the parent strain or from the lysine-independent strain and is selected for by growth in a medium containing hydroxylysine. The three strains appeared to be identical by all tests employed except in their responses to lysine and hydroxylysine.
\end{abstract}

\section{INTRODUCTION}

It has been reported that Streptococcus faecalis ATCC 8043 has an absolute requirement for lysine (Dunn, Shankman, Camien \& Block, 1947). The growth of this organism is inhibited by hydroxylysine despite the fact that it can utilize this lysine analogue for both protein and cell-wall synthesis in the presence of a sub-optimal concentration of lysine (Smith \& Henderson, 1964). In view of these characteristics the strain has been given the designation Lys ${ }^{-} \mathrm{OHLys}^{3}$. The designation $\mathrm{Lys}^{-}$or $\mathrm{Lys}^{+}$ is given to strains which are lysine-dependent or lysine-independent, respectively. Hydroxylysine-sensitivity and resistance are designated as OHLys ${ }^{\mathbf{s}}$ or OHLys ${ }^{\mathrm{r}}$, respectively.

It was observed that a heavy inoculum of $\mathrm{Lys}^{-} \mathrm{OHLys}^{8}$ added to either lysinefree medium or lysine-free medium containing hydroxylysine ( 3 to $4 \mu \mathrm{g}$. $/ \mathrm{ml}$.) gave observable growth in each case after specified incubation periods (Smith \& Henderson, 1964). Examination of cultures obtained under these conditions of growth revealed that they differed from each other and from the parent Lys-OHLys ${ }^{8}$ strain with respect to their response to lysine and hydroxylysine. This communication describes the nature of these two variants which arose so readily from Streptococcus faecalis 8043 .

\section{METHODS}

Streptococcus faecalis ATCC 8043 and two mutants whose isolation has been described (Smith \& Henderson, 1964) were used. They were grown at $37^{\circ}$ in a standard

* Present address: Department of Experimental Surgery, Veterans Administration Hospital, Minneapolis, Minnesota 55417, U.S.A. 
liquid medium (Henderson \& Snell, 1948) which contained various amounts of L-lysine and/or the mixture of hydroxy-D,L-lysine and allohydroxy-D,L-lysine. Growth was measured at intervals by determining the extinction at $660 \mathrm{~m} \mu$ with a Coleman Junior spectrophotometer.

The total viable count was determined by making the appropriate dilutions of the culture, shaking the diluted culture, with glass beads at each stage of dilution, and plating a sample, in triplicate, on $2 \%$ agar plates prepared from standard-growth medium supplemented with lysine ( $100 \mu \mathrm{g}$. $/ \mathrm{ml}$.). The plates were incubated at $37^{\circ}$ for $24 \mathrm{hr}$. Total lysine-independent counts were made in a similar manner except that lysine-free medium was used. Numbers of lysine-dependent cocci represented the difference between the total viable count and the lysine-independent count.

Fermentation tests were conducted in standard growth medium in which glucose was replaced by the carbohydrate under test at an equimolar concentration ( $0^{\cdot}$ I I M). Standard growth medium either with $6.5 \% \mathrm{NaCl}$ or at $\mathrm{pH} 9.6$ was sterilized by filtration for tolerance tests.

\section{RESULTS}

The isolations of the two mutant strains originally found by Smith \& Henderson (I964) have been repeated under controlled conditions with a purified culture of the Lys $^{-} \mathrm{OHLys}^{8}$ strain with the same results as previously obtained. The parent strain and the two mutants have been compared with respect to their performance in certain fermentation and tolerance tests. The results are presented in Table 1 . The three strains fermented the same carbohydrates although not all carbohydrates to which Strepto-

Table I. Carbohydrate fermentation and response to various growth conditions of the three strains of Streptococcus faecalis

\begin{tabular}{|c|c|c|c|}
\hline & Lys-OHLys ${ }^{8}$ & Lys $^{+}$OHLys ${ }^{8}$ & Lys $^{+} \mathrm{OHI}$ \\
\hline Sugar & \multicolumn{3}{|c|}{ Carbohydrate fermentation } \\
\hline Glucose & $t^{*}$ & $+^{*}$ & $t^{*}$ \\
\hline Maltose & + & + & + \\
\hline Lactose & $+t$ & $+t$ & $+t$ \\
\hline Mannitol & - & - & - \\
\hline Sorbitol & - & - & 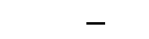 \\
\hline Arabinose & - & - & - \\
\hline Salicin & + & + & + \\
\hline Sucrose & + & + & + \\
\hline \multirow[t]{2}{*}{ Trehalose } & + & + & + \\
\hline & \multicolumn{3}{|c|}{ Temperature of growth } \\
\hline $10^{\circ}$ & $+t$ & $+t$ & $+t$ \\
\hline $37^{\circ}$ & + & + & + \\
\hline \multirow[t]{2}{*}{$45^{\circ}$} & + & + & + \\
\hline & \multicolumn{2}{|c|}{ Special conditions } & \\
\hline $\begin{array}{l}\text { Heated inoculum and } \\
\text { incubation at } 37^{\circ} \ddagger\end{array}$ & - & - & - \\
\hline Growth in $6.5 \% \mathrm{NaCl}$ & - & - & - \\
\hline Growth in $\mathrm{pH} 9.6$ & $+t$ & $+t$ & + \\
\hline
\end{tabular}

- A plus (+) represents growth, a minus (-) represents no growth.

$\dagger$ Growth was observed only after 3-5 days of incubation.

$\ddagger$ The culture was heated at $60^{\circ}$ for $10 \mathrm{~min}$. in a water bath before it was used to inoculate fresh growth medium. 
coccus faecalis is reported to respond (Bergey's Manual of Determinative Bacteriology, 7 th ed., 1957) were utilized by these organisms. The apparent intolerance to $6.5 \%$ $\mathrm{NaCl}$ was not expected. It has been proposed that $S$. faecalis 8043 (the Lys-OHLys ${ }^{8}$ strain) be reclassified to Streptococcus faecium var. durans (Coultas, Albrecht \& Hutchinson, 1060). The differences noted may reflect the characteristics of $S$. faecium (Diebel, Lake \& Niven, 1963).

It has been shown (Dunn et al. 1947) that Streptococcus faecalis 8043 requires threonine, methionine, lysine and isoleucine for growth. In Escherichia coli (Umbarger \& Davis, 1962) these four amino acids share certain common steps in their synthesis, i.e. the conversion of aspartic acid to aspartic semialdehyde (Black \& Wright, I955). Because of this relationship, also found in other bacteria, it was of interest to determine whether lysine-independence was accompanied by threonine- and methionineindependence.

Table 2. Comparison of the number of lysine-independent bacteria in different samples of the same culture, and a series of different cultures

\begin{tabular}{|c|c|c|c|}
\hline \multirow[b]{2}{*}{ Number of cultures } & Expt. I & \multicolumn{2}{|c|}{ Expt. 2.} \\
\hline & 50 & 100 & 1 \\
\hline Volume of cultures (ml.) & 0.3 & 0.3 & 100 \\
\hline Number of samples tested & 50 & 100 & 100 \\
\hline Volume of samples tested ( $\mathrm{ml})$. & 0.3 & 0.3 & 0.3 \\
\hline & \multicolumn{3}{|c|}{ Number of samples } \\
\hline o & 14 & $3 \mathrm{I}$ & 0 \\
\hline $1-10$ & 4 & 1 & 0 \\
\hline $11-20$ & 0 & 7 & 0 \\
\hline $21-30$ & $\mathbf{I}$ & 15 & 7 \\
\hline $31-40$ & 2 & 13 & 42 \\
\hline $41-50$ & 6 & 8 & 47 \\
\hline $51-100$ & 4 & 15 & 4 \\
\hline $101-300$ & I & 10 & 0 \\
\hline$>300$ & 18 & 0 & 0 \\
\hline Bacteria per culture & $9.4 \times 10^{4}$ & $1.0 \times 10^{5}$ & - \\
\hline Mutation rate & $7.8 \times 10^{-5}$ & $9.7 \times 10^{-6}$ & 一 \\
\hline
\end{tabular}

The two mutant strains and the parent strain were grown in media containing various amounts of threonine or methionine. Both mutants had an absolute requirement for these amino acids. Thus lysine-independence is specific and does not result in the concomitant relief of threonine and methionine requirements.

The autolytic behaviour of the Lys ${ }^{-} \mathrm{OHLys}^{\mathrm{B}}$ strain has been previously demonstrated (Smith, Newman, Leach \& Henderson, 1962) in various media. This strain is susceptible to lysine-depletion lysis as is Streptococcus faecalis 9790 (Shockman et al. 196I). The two mutant strains, Lys ${ }^{+} \mathrm{OHLys}^{\mathrm{s}}$ and $\mathrm{Lys}^{+} \mathrm{OHLys}{ }^{\mathrm{r}}$, are not subject to lysine depletion lysis (Smith \& Henderson, 1964) because of their lysine biosynthetic capability; however, experiments conducted as previously described (Smith et al. 1962) indicated that the mutant strains did have lytic enzymes. Like the parent strain (Smith et al. 1962), the rate of lysis of the mutant strains was dependent on the suspending medium.

The rate of mutation to lysine-independence was determined by the fluctuation test (Luria \& Delbrück, I943). From the data presented in Table 2 it was calculated that 
the rate was 7.8 to $9.7 \times 10^{-5}$ mutations per cell per generation. The data further indicated that the acquisition of this trait did not result from the lack of lysine in the medium.

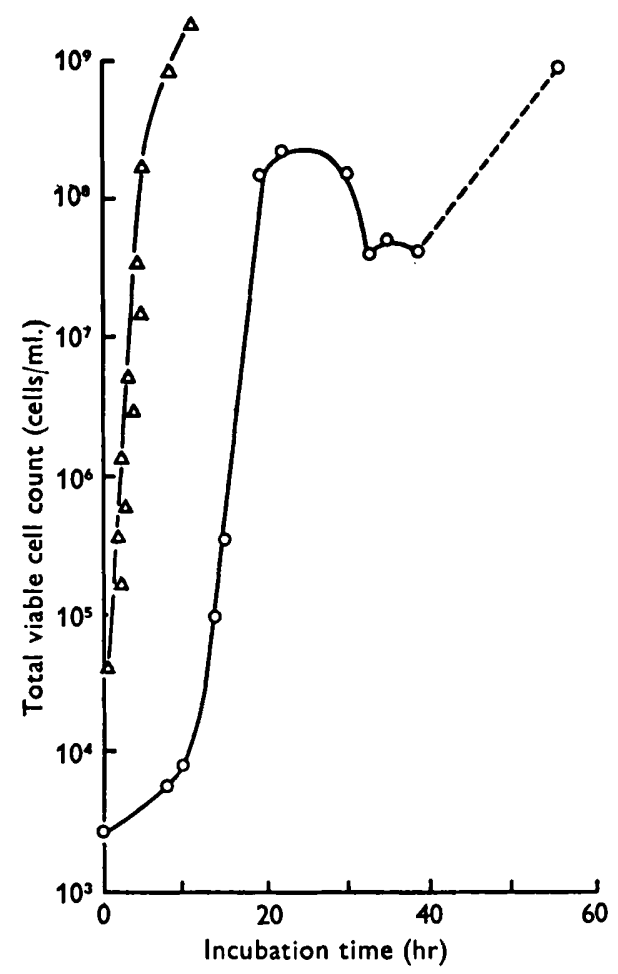

Fig. 1. Growth of the Lys-OHLys ${ }^{8}$ strain in lysine-free and lysine-supplemented medium. The total viable count represents the average of triplicate samples. $(\triangle-\triangle)$, growth in lysinesupplemented medium; $(\bigcirc-\bigcirc)$, growth in lysine-free medium. The dashed line in the latter curve shows that between the 38 th and 54 th $\mathrm{hr}$ of incubation there was a substantial increase in viable cell count.

The mutation to lysine independence in Streptococcus faecalis was observed to occur with regularity after $90 \mathrm{hr}$ under conditions where normal amounts of inoculum ( $\mathrm{IO}^{3}$ washed cocci) were added to a medium which by independent assay with Leuconostoc mesenteroides was shown to be very low in lysine. Sub-culturing the growth revealed the presence of lysine-independent cells. In similar experiments, Lys ${ }^{+} \mathrm{OHLys}^{\mathrm{r}}$ cells appeared when Lys-OHLys ${ }^{8}$ cells were grown in a lysine-free medium containing hydroxylysine $3 \mu \mathrm{g} . / \mathrm{ml}$. The 'leakiness' of the lysine synthetic pathway in the parent strain was established by two studies in which the growth rates were measured by making viable counts throughout the growth period. In the first experiment (Fig. I) an inoculum of approximately $10^{4}$ cocci from a log. phase culture of the Lys ${ }^{-}$ $\mathrm{OHLys}^{8}$ strain were added to $10 \mathrm{ml}$. of lysine-free medium or to $10 \mathrm{ml}$. of lysinesupplemented medium. The viable count was determined on lysine-supplemented agar medium. In the lysine-free medium the population did not change appreciably for about $4 \mathrm{hr}$, then logarithmic growth ensued at such a rate as to indicate a generation time of $37 \mathrm{~min}$. In the lysine-supplemented medium growth was not delayed and the 
generation time was $29.5 \mathrm{~min}$. The maximum viable population was $10^{\circ} \mathrm{cocci} / \mathrm{ml}$. with lysine, but without lysine the maximum was $10^{8}$ cocci $/ \mathrm{ml}$., and following a short stationary phase the viable population decreased. At $54 \mathrm{hr}$, however, Lys ${ }^{+}$ OHLys cells were detected in the lysine-free medium when the viable population had reached $10^{9} \mathrm{cocci} / \mathrm{ml}$, suggesting that some time during the later phases of logarithmic growth mutants had appeared.

In another experiment viable $\mathrm{Lys}^{+}$cocci were also counted, beginning in the later stage of exponential growth and continuing for an additional $40 \mathrm{hr}$. This experiment, summarized in Fig. 2, showed that while viable Lys $^{-} \mathrm{OHLys}^{\mathrm{s}}$ cells were disappearing the Lys ${ }^{+} \mathrm{OHLys}{ }^{8}$ strain was growing and that the latter strain emerged as the dominant

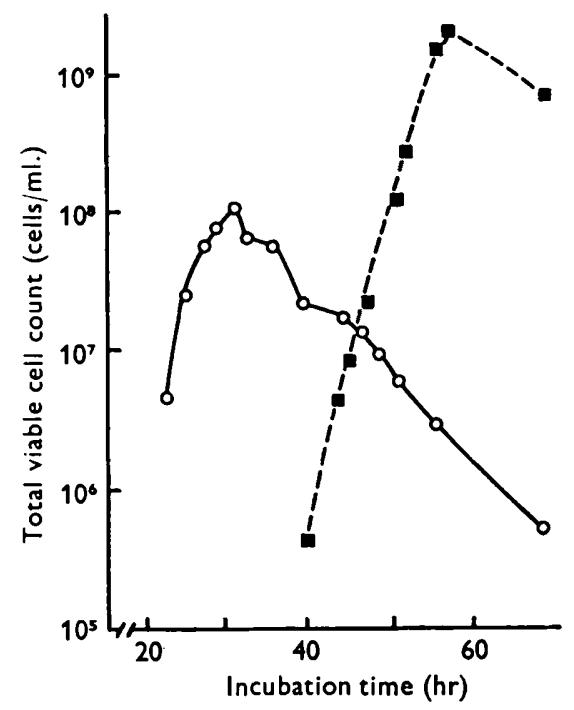

Fig. 2. Growth of the Lys $-\mathrm{OHLys}^{8}$ strain in lysine-free medium and the emergence of the Lys $^{+}$OHLys $^{8}$ strain as the dominant population. The experiment was conducted as described in the legend for Fig. I except that in addition the total viable lysine-independent cell count was made. ( $\bigcirc-\bigcirc)$, the lysine-dependent viable cell count; ( $\square-.--\square)$, the lysineindependent viable cell count.

population. The appearance of mutant cells in large numbers occurred when the population of Lys ${ }^{-}$cells was declining rapidly approximately $40 \mathrm{hr}$ after inoculation. As in the previous experiment the mutant population continued to increase until it reached a maximum population of approximately $10^{9} \mathrm{cocci} / \mathrm{ml}$.

\section{DISCUSSION}

The parent and mutant strains have been compared and have been found to respond in the same way to all tests employed except for those previously described which involve the responses to lysine and hydroxylysine (Smith \& Henderson, 1964). The present work has demonstrated that the characteristic of total lysine-independence resulted from a mutational event. Hydroxylysine-resistance has also been demonstrated to result from a mutational event involving the lysine-transport system (J. D. Friede, D. P. Gilboe and L. M. Henderson, to be published). 
The Lys $-\mathrm{OHLys}^{\mathrm{B}}$ strain has limited lysine biosynthetic capacity. In these experiments precautions were taken to assure that the medium was lysine-free and, in addition, a small inoculum was used. In the use of such an inoculum it was assumed that the growth rate for both parent and mutant was the same in lysine-supplemented medium and when a mutation occurred the lysine-dependent strain remained the dominant population as growth proceeded. In support of this assumption it was found that in an early stationary phase culture of Lys ${ }^{-} \mathrm{OHLys}^{8}$ cells in lysine-supplemented medium there were from 150 to $120 \mathrm{Lys}^{+} \mathrm{OHLys}^{8} \mathrm{cocci} / \mathrm{ml}$. in a total population of $4.3 \times 10^{9}$ cocci/ml. The use of a small inoculum, therefore, limited the possibility of a lysineindependent cell being present. This observation and the stability of the lysine-dependence trait of the parent organism which has been carried on lysine-containing medium suggests that the Lys ${ }^{-}$strain has a selective advantage over the Lys ${ }^{+}$strain under these culture conditions. Zamenhof \& Eichhorn (1967) have presented evidence that mutants of Bacillus subtilis which have lost a biosynthetic function have a selective advantage over the parent strain. This observation provides an adequate explanation for the relative stability of the $\mathrm{Lys}^{-} \mathrm{OHLys}{ }^{8}$ strain which has been carried in many laboratories over a period of years.

Despite the limited lysine biosynthetic capability of the Lys ${ }^{-} \mathrm{OHLys}^{\mathrm{B}}$ strain certain pathway enzymes, aspartokinase, dihydrodipicolinic acid synthetase and diaminopimelic acid decarboxylase, found in mutant strains, could not be detected in cell-free extracts of the parent strain (Gilboe, Friede \& Henderson, 1968). Whether the lysineindependence of the mutant results from the relief of a pathway block or the derepression of part or all of the pathway has not been determined.

During the course of the growth of the Lys ${ }^{-} \mathrm{OHLys}^{8}$ strain in lysine-free medium a mutational event occurs resulting in lysine-independence. In earlier work (Dunn et al. 1947; Smith, 1963) growth of the parent strain in a rich lysine-free medium could not be detected nor was the outgrowth of the Lys ${ }^{+} \mathrm{OHLys}{ }^{8}$ strain observed. The results of the 'fluctuation test' suggest that the lysine-free medium used in this work permitted limited growth of the Lys-OHLys ${ }^{8}$ strain and favoured the selection of the mutant strain which appeared.

In Fig. I and again in Fig. 2 it can be seen that in lysine-free medium the LysOHLys $^{8}$ strain grew to a maximum viable population of only $10^{8}$ cocci $/ \mathrm{ml}$. and, following a short stationary phase, the viable population decreased. It is postulated that the failure of $\mathrm{Lys}^{-} \mathrm{OHLys}^{8}$ cells to grow to a population of $10^{8} \mathrm{cocci} / \mathrm{ml}$. as it did in lysine-supplemented medium resulted from an imbalance between the rate of production of lysine, which is essential for protein and cell-wall synthesis, and lysis of the culture. If cell-wall subunit production were limited by lysine and the lytic system functions in the incorporation of subunits into the cell-wall mucopeptide (Shockman et al. 196I), then when no subunits are present lysis of the cell may ensue. It should be pointed out that when the population reached $10^{8} \mathrm{cocci} / \mathrm{ml}$. the $\mathrm{pH}$ value of the medium was found to have dropped to $\mathrm{pH} 6 \cdot 0$, the optimum for the lytic enzymes (unpublished observations).

The sequence of mutational events which convert the Lys-OHLys ${ }^{8}$ strain to the Lys $^{+} \mathrm{OHLys}^{\mathrm{B}}$ strain is not known. It has been shown, however, that Lys ${ }^{+} \mathrm{OHLys}^{\mathrm{r}}$ cells can be isolated from cultures of the Lys ${ }^{+} \mathrm{OHLys}^{8}$ strain. Mutation to hydroxylysine resistance followed by mutation to lysine independence has not been excluded. but there is no obvious basis for selecting a Lys-OHLys ${ }^{\mathrm{r}}$ strain. 
This investigation was supported by U.S. Public Health Service, Department of Health, Education and Welfare, under Grant No. AM-07984.

This work was part of a dessertation submitted by the senior author in partial fulfilment of the requirements for the Ph.D. (Biochemistry) to the Graduate Faculty of the University of Minnesota. Scientific Journal Series No. 6319. Agricultural Experiment Station, University of Minnesota, St Paul, Minnesota.

\section{REFERENCES}

Black, S. \& WRIGHT, N. G. (1955). Aspartic $\beta$-semialdehyde dehydrogenase and aspartic $\beta$-semialdehyde. J. biol. Chem. 213, 39.

Coultas, M. K., Albrecht, A. M. \& Hutchinson, D. J. (1960). Strain variation within Streptococcus faecium var. durans. J. Bact. 92, 516.

Diebel, R. H., Lake, D. E. \& Niven, C. F., Jun. (1963). Physiology of enterococci as related to their taxonomy. J. Bact. 86, 1275.

Dunn, M. S., Shankman, S., Camien, M. N. \& Block, H. (1947). The amino acid requirements of twenty three lactic acid bacteria. J. biol. Chem. 168, I.

Gilboe, D. P., Friede, J. D. \& Henderson, L. M. (1968). Effect of hydroxylysine on the biosynthesis of lysine in Streptococcus faecalis. J. Bact. 95, 856.

Henderson, L. M. \& SNell, E. E. (1948). A uniform medium for determination of amino acids with various microorganisms. J. biol. Chem. 172, 15.

Luria, S. E. \& DelbrüCK, M. (1943). Mutations of bacteria for virus sensitivity to virus resistance. Genetics 28, $49 \mathrm{I}$.

Shockman, G. D., Conover, M. J., Kolb, J. J., Phillips, P. M., Riley, L. S. \& Toennis, G. (I96i). Lysis of Streptococcus faecalis. J. Bact. 81, 36.

SмrтH, W. G. (1963). Effect of hydroxylysine on bacteria. Ph.D. thesis, Oklahoma State University, Stillwater, Oklahoma.

SMith, W. G. \& Henderson, L. M. (1964). Relationships of lysine and hydroxylysine in Streptococcus

Smith, W. G., Newman, M., Leach, F. R. \& Henderson, L. M. (1962). The effect of hydroxylysine on cell wall synthosis and cell stability in Streptococcus faecalis. J. biol. Chem. 237, I 198. faecalis and Leuconostoc mesenteroides. J. biol. Chem. 239, 1867.

Umbarger, E. \& Davis, B. D. (1962). In The Bacteria. Ed. by I. E. Gunsalus and R. Y. Stanier. Vol. 3, p. 167. New York: Academic Press.

ZAMENHOF, S. \& EICHHORN, H. H. (1967). Study of microbial evolution through loss of biosynthetic functions: establishment of 'defective' mutants. Nature, Lond. 216, 456. 